\title{
A Prospective Evaluation of Structures and Processes Associated with the Quality of Mental Health Care in the Kingdom of Saudi Arabia
}

\author{
Yaqoub Al Mousa ${ }^{a}$ Patrick Callaghan ${ }^{b}$ Maria Michailc \\ aResearch Management, Al Omran General Hospital, Al Hasa Health Cluster, Ministry of Health, Hofuf, Saudi Arabia; \\ ${ }^{b}$ School of Applied Sciences, London South Bank University, London, UK; 'Institute for Mental Health, School of \\ Psychology, University of Birmingham, Birmingham, UK
}

\section{Keywords}

Evaluation - Mental health · Mental health services · Quality of health care $\cdot$ Saudi Arabia

\begin{abstract}
Introduction: Quality of care is important for improving outcomes of service users in inpatient mental health settings. There is a lack of research investigating the predictors of quality of mental health care and their relationship with service user outcomes, particularly in Saudi Arabia, despite the high priority given to this in the Kingdom of Saudi Arabia (KSA) national health strategy. Objective: This study investigates the factors associated with the quality of mental care and their relationship with service users' outcomes, disability, disease, discomfort, and dissatisfaction, using Donabedian's framework. Methods: A questionnaire survey was distributed to 176 nurses and 321 service users in an inpatient psychiatric hospital in Saudi Arabia. Data were gathered on structures (staff and service users' characteristics) and processes (staff attitudes to mental illness, competency, and level of interaction with service users) linked to service users' outcomes. Results: Multilevel modelling showed that service users' characteristics, for example, age, marital status, employment status, educational level, area of residence, and diagnosis, significantly predicted disability. With 1 exception
\end{abstract}

(unemployment), none of the service users' characteristics was found to be a statistically significant predictor of disease, although educational level was found to be a significant predictor of discomfort and dissatisfaction. Age and years of experience were found to significantly predict service user disability among nurses, and years of experience was a significant predictor of users' dissatisfaction. Nurses' competence was found to be a statistically significant predictor of disability, while their attitudes to mental illness and their interactions with users did not significantly predict the latter's outcomes. Conclusions: These findings suggest that factors other than those studied here have more currency in relation to quality of care in Saudi Arabia, despite these factors have been shown to relate to quality of care outside the KSA. A more detailed qualitative approach to better understand factors relevant to the quality of mental care in Saudi Arabia is reported by the authors in a concomitant article.

(C) 2021 The Author(s)

Published by S. Karger AG, Basel

\section{Introduction}

Quality of care (QoC) is important for improving outcomes of service users in inpatient mental health settings. A widely accepted international framework for assessing QoC is Donabedian's structure, process, and outcome
(C) 2021 The Author(s)

Published by S. Karger AG, Basel

This is an Open Access article licensed under the Creative Commons Attribution-NonCommercial-4.0 International License (CC BY-NC) (http://www.karger.com/Services/OpenAccessLicense), applicable to the online version of the article only. Usage and distribution for commercial purposes requires written permission.
Correspondence to:

Yaqoub Al Mousa,yymm_2004@yahoo.com 
approach. Each of these impacts the others, leading to improved QoC [1]. "Structure" refers to such components as the hospital ward setting, service users, and health-care provider's resources. These create the system through which health care is received and delivered. Meanwhile, "process" refers to the way in which care is provided for service users, thus affecting outcomes. These outcomes are the result of actions arising from the process. Finally, service users' health care "outcomes" are wide-ranging and need to be considered when investigating QoC.

A classic list of medical outcome measures, capturing the effect of the care process on service users' health and well-being, is expressed as the $5 \mathrm{D}$ 's: death, disability, disease, discomfort, and dissatisfaction [2]. According to Lohr, these domains are central to a range of outcomes that should be considered when evaluating QoC in health systems.

A detailed review of literature using a systematic approach [4-10] examined the impact of Donabedian's framework as means of systematically investigating the quality of mental health care. The results of this review showed the possibility of understanding QoC through Donabedian's lens, but few studies used it to understand QoC in mental health. The review showed that several approaches to capture structure, process, and outcomes are apparent. Reported methodological concerns such as inadequate and unrepresentative sample sizes and low response rates to surveys are evident. Studies used a range of either quantitative or qualitative methods and were conducted in developed countries exclusively. The aims of the current study were to investigate structure and processes in service provision and their relationship with quality of mental care - service user outcomes in the Kingdom of Saudi Arabia (KSA).

\section{Materials and Methods}

\section{Study Design}

This work used a quantitative survey conducted at a mental health hospital in the KSA. The hospital is a secondary-level referral hospital operated by the Ministry of Health $(\mathrm{MOH})$, with a 670bed capacity and comprising 18 wards, which covers people of all regions throughout the country.

\section{Sampling and Participants}

Total sampling was used to recruit all 321 service users admitted to 14 inpatient psychiatric wards ( 11 male/ 3 female wards) diagnosed with mental disorders according to DSM-V, as well as all 176 nurses working in these wards under study, based on specific eligibility criteria. These service users linked to specific nurses that are defined as their primary care providers in inpatients wards, and each nurse was assigned the care of an average of 8 service users, with a ward capacity ranging from 25 to 40 beds.

We were seeking to detect a medium effect size of 0.01 and have estimated that with a power of $80 \%$, with a set of 6 "independent" variables, 134 participants for each category (staff and service users) were required. Estimating a 50\% non-response rate to the survey based upon previous studies, a minimum of 300 participants in each category was required [10].

\section{Inclusion Criteria}

1. All staff employed at the study site for more than 1 year, working in inpatient settings and providing direct care to service users.

2. Service users aged 18 years or over, diagnosed with any form of mental disorder conforming to the Diagnostic and Statistical Manual of Mental Disorders, fifth Ed (DSM-V) [11] and admitted to inpatient psychiatric wards, able to speak Arabic, and able to give informed consent.

\section{Exclusion Criteria}

1. Staff who had been caring for mentally ill service users for less than 1 year.

2. Service users with known organic brain damage or who were unable to consent.

\section{Data Collection}

Data collection took place over a 6-month period from June to December 2014. Following written consent from participants, a combination of questionnaires and participant observation of staff-service users' interactions were used for data collection.

\section{Measures}

Structure Measures

A multipurpose questionnaire that covers a range of structural variables was developed to capture the participants' sociodemographic characteristics (staff and service users) and the admission ward features. These were the staff characteristics sheet (SCS) (age, gender, nationality, qualifications, years of experience in the hospital, attendance of psychiatric training courses, and staff numbers), a service user characteristics sheet (age, gender, marital status, employment status, educational level, area of residence, and diagnosis), and a ward characteristics sheet in terms of number of beds, the availability of essential infrastructure in the ward, and the availability of essential drugs for psychiatric service users.

\section{Process Measures}

Three surveys were administered to psychiatric nurses in the present study: the Attitudes towards Acute Mental Health (ATAMH-33), Competency Assessment Tool-Mental Health (CAT$\mathrm{MH}$ ), and the Interaction-Observation Checklist (IOC).

\section{Attitudes towards Acute Mental Health}

ATAMH-33 is a self-reported questionnaire developed by Baker et al. [12]. It contains 33 questions measuring the attitudes and knowledge of health professionals in acute mental health care settings. The ATAMH-33 has been widely used in Arabic countries $[13,14]$ and has therefore already been translated into Arabic and tested by the original authors, who reported a Cronbach's a of 0.72 . 
Competency Assessment Tool-Mental Health

The CAT-MH was developed by Clasen et al. [15] and consists of 26 items that measure the core competencies of health professionals working in inpatient psychiatric facilities. The instrument has high internal consistency and high reliability scores for each of the subscales, with a Cronbach's $\alpha$ of 0.93 and 0.95 for the knowledge and benefit subscales, respectively.

In pursuit of the general aim of this study, the Likert scale responses (anchors) of the CAT-MH were amended to assess levels of staff competency in the delivery of mental health care, since these responses were originally designed to focus primarily on determining whether mental health workers considered a particular skill or knowledge to be important. The scale items were retained in the same form, following the amendment of the anchors. For the amended competency scale, the following question was posed: "How competent are the workers whom you supervise in providing direct mental health care?" The new anchors were scored on a 5 -point Likert-type scale ( 1 = not competent, 2 = somewhat competent, 3 = uncertain, $4=$ competent, $5=$ highly competent). An inter-rater reliability, checked prior to the study, between 2 raters was $0.81(p=0.000)$. Permission to utilize the CAT-MH scale (as well as in its translated and amended form) was obtained from the original author.

\section{Interaction-Observation Checklist}

The IOC was originally designed to assess the frequency and characteristics of staff-service user interaction. A category system (IOC) for classifying observed phenomena is the most common approach to conduct structured observations, where operational definition of the behaviours and characteristics are clearly demonstrated [16]. The IOC comprises 4 (observational) categories of interactional behaviour: individual verbal (IV), individual non-verbal (INV), group verbal (GV), and group nonverbal (GNV). Each of these has positive, neutral, and negative sub-categories for all staff-service user interactions and 2 categories of non-interactive behaviour: ignoring the service user (IG), and solitary task-oriented (SOL) or other activities. To determine the presence or absence of positive, neutral, or negative behaviour interactions, the researcher used observation criteria that were similar to those employed in previous studies on staffservice user interaction [17]. It was felt that basing these criteria on those used in previous studies would allow comparisons to be made with the behaviour of professionals in other health organizations. Using the IOC, data are generated to indicate the frequency of each category and overall rates of staff-service user interaction. The IOC has been employed in several studies on psychiatric residential environments and has been reported as having high inter-observer reliability checks, ranging from 88.7 to $96.9 \%[17,18]$.

\section{Outcome Measures}

In this study, we focussed mainly on the use of standard instruments for measurement of service user-reported outcomes, in domains of the " $5 \mathrm{D}$ 's" including disability measured by the Social Functioning Scale (SFS) [19], disease symptoms measured by the Brief Psychiatric Rating Scale (BPRS) [20], discomfort measured by Glasgow Antipsychotic Side-Effect Scale (GASS) - most of the service users admitted to the hospital had a diagnosis of a psychotic disorder [21], and dissatisfaction measured by the Client Satisfaction Questionnaire (CSQ-8) [22]. We sought to include mortal- ity rates as a measure of death, but the hospital reported that it did not record these and the rates were reportedly unavailable elsewhere in the Kingdom of Saudi Arabia.

\section{Procedure}

Surveys

None of the study instruments, except the ATAMH-33, had been used in an Arabic-speaking country, so they were translated from English to Arabic, back-translated to English and checked for discrepancies by an independent bilingual translator and the lead author, a native Arabic speaker. A pilot study with 10 participants for each category, including staff and service users confirmed participants' acceptability and understanding of the Arabic version of all instruments. The English version of study measures, where applicable, was used for those staff who did not speak Arabic. The psychometric properties of the translated instruments included in this study were very good (see online suppl. Table 1; see www.karger.com/doi/10.1159/000515206 for all online suppl. material). Permission to translate and use the study instruments, where applicable, was obtained from all original authors.

\section{Observation}

Prior to any action being performed, the location of the sites to be observed must be determined. As with any other concerns, the selection of sites in structured observation, using a random sampling procedure, can help reduce any worries that might arise spontaneously during the data collection process [23]. This will in turn enable the researcher to generalise the study findings. In this current study, observations of staff-service user interaction were conducted across 6 different admission wards ( 4 male/ 2 female), with a ward capacity ranging from 25 to 40 beds. These wards were randomly selected by drawing numbered slips of paper generated by the researcher to ensure representativeness. Random selection was achieved by numbering the wards $(n=14)$ consecutively from 1 to 14 , whereby an independent research professional, not connected to the study, drew correspondingly numbered slips of paper at random from a bowl containing equal numbers for each ward. This process was repeated until the required number of slips of paper had been drawn.

Staff-service user interaction was thus observed for a 4-week period, during the daytime shift from 07:00 to 15:00. Each participating ward was observed for $1 \mathrm{~h}$ per day on 3 days a week using the IOC. The daytime period was selected in accordance with other mental health studies [17], which found that this time period corresponds to what is known as the "therapeutic day" and it is during this period that the greatest number of interactions is likely to occur. The selected daytime period clearly offered a better opportunity for a representative observation, in the sense of capturing typical care, possibly offering a better reflection of the way in which interactions affected service users' outcomes.

In addition, given the potential for the Hawthorne effect, it is possible and even likely that staff endeavoured to be "on their best behaviour," as they knew that they were being observed. The Hawthorne effect is often cited in criticisms of observational studies of workplace behaviour, where there is the aim of improving performance [24]. This effect suggests that additional attention should be paid to the data collection process, in order to avoid or minimize the potential for the Hawthorne effect. For example, during the 
data collection, on different occasions and sometimes concurrently, the researcher(s) manipulated the length and timing of the observation periods. This virtually eliminated the possibility of bias on the part of the staff or researcher. In addition, all key components of observational research were identified (including methodological considerations), which ruled out the possibility of distortion in the study. Another strategy adopted to avoid or reduce the Hawthorne effect involved covert data collection, whereby the staff were not informed about the data to be gathered (the observation categories of staff behaviour), prior to the data collection. Such a strategy keeps staff ignorant of the information that the researcher is interested in collecting. Furthermore, given that on average, several hundred instances of behaviour were observed for each targeted staff member, it is unlikely that the observed behaviours could be wholly unreliable or unrepresentative of usual staff behaviour.

Prior to conducting the observation, the lead author (Y. Al Mousa) familiarized himself with the data collection tool and trained 2 female nurse researchers from different wards at the named hospital (including mastery of the observation procedures and category definitions). This was for the purpose of collecting observation data on behalf of the researcher in the female wards, as the researcher (being male) was not allowed direct access to female wards, according to Saudi policy. It is essential to train observers, so that each behaves in the same way when collecting information through observation. These training sessions lasted for 2 weeks at a frequency of $3 \mathrm{~h}$ a day in 2 male admission wards, where all nursing staff were female. During the sessions, the lead author and nurse researchers conducted observations independently on the same ward, observing the same activities and behaviours with the same staff at the same time. To ensure that these observations were contemporaneous, a verbal cue was given by 1 selected observer at the beginning of each 5-min interval for $1 \mathrm{~h}$ each day. After this, inter-observer reliability checks were carried out to assess the reliability of the observations, before the actual observations took place, with each observer operating independently. The reliability of these observations was established by calculating Cohen's kappa $(\kappa)$, whereby inter-rater agreement was examined and compared between the 3 observers. High agreement between the 3 observers $(\kappa=0.83, p<0.001)$ was subsequently found. In addition, reliability was achieved for the observations in the 2 male admission wards, calculated using the percentage level of agreement between the 3 observers. These reliability values were calculated using the following formula: (no. of agreements/no. of agreements + no. of disagreements $\times 100)$. Overall, inter-rater reliability totalled $82.8 \%$ in 1 ward, but this increased to $87.8 \%$ for observation conducted on the second day in another ward.

Ward managers provided Y. Al Mousa with sampling schedules created by him for the purpose of specifying the wards, times and target staff members to be observed. During the data collection, Y. Al Mousa and the trained 2 female nurse researchers entered the wards, identified the target staff members, and recorded their behaviour with each service user every $5 \mathrm{~min}$. At each interval, observation began by observing the first nurse encountered and continued until all nurses had been observed. Nurses' interactions with service users at the observed time were recorded on a clipboard using predefined categories in the IOC.

\section{Data Analysis}

Statistical Analysis

Data were compiled, checked for completeness, and entered into SPSS (version 22). Descriptive characteristics were summarized in numbers and percentages. Following this, multilevel fixed effects modelling (regression model) was carried out using MLwiN 2.35 statistical software, with service users' characteristics against outcomes as the dependent variables, with nurses' characteristics and processes of care on each ward as the explanatory variables, in the form of aggregated group values by deriving a new variable that summarized the information as the average (mean). Each variable was added to the multilevel modelling in a sequential manner, 1 variable at a time.

\section{Data Description}

Data were collected from nurses and service users across 14 wards. The data consequently had a 2-level hierarchical structure, with service users represented at level 1 , nested within wards at level 2. Multilevel modelling analysis was used because the data were collected at different levels or unit of analysis, and 1 level was nested in the other [25]. The levels of analysis represented in this study were: (1) service user level, with data obtained from service users admitted to various psychiatric wards, and (2) ward level, with data representing ward characteristics. All these data were obtained from the nurses assigned to various hospital wards. Thus, individual service users were nested within the hospital wards.

Accordingly, the dataset was sorted in the MLwiN spreadsheet, so that all records for the same highest-level unit were grouped together. Within this group, all records for a particular lower-level unit were linked. Moreover, the data on nurses were arranged in the MLwiN data sheet, based on the number of service users in each ward (as a flat file). At each level of the hierarchy, there were 2 main types of variable: level 1 variables (service user-level), which included socio-demographic variables (service users' characteristics) and dependent variables (i.e., disability, disease, discomfort, and dissatisfaction), and level 2 variables (ward-level), which included the socio-demographic variables and process variables for the nurses. The variables for the levels of analysis are described below.

\section{Level 1 Variables (Service User Level)}

1. Service users' characteristics included age, gender, marital status, employment status, educational level, area of residence, and diagnosis. Each parameter has a measure of possible values: age was used as a continuous variable (in years); gender was categorized as male or female; marital status was categorized into single, married, divorced, and widowed; employment status was categorized as retired, employed, or unemployed; and educational level was categorized into illiterate, primary school, intermediate school, secondary school, college (diploma), graduate, and postgraduate. Service users were categorized into western region, eastern region, central region, north region, and south region. Finally, individual diagnosis was allocated to diagnostic categories of schizophrenia, personality disorder, bipolar disorder, substance-related disorder, and depression.

2. Dependent variables: disability was defined as a total score, calculated as the psychiatric service user's ability to engage in necessary social activities (measured using SFS); disease was defined as the total score calculated for specific symptoms of psychiatric service users, based on service users' self-reporting (measured using BPRS); discomfort was defined as the total 
score calculated for service users' experience of the side effects of psychiatric medication (measured using GASS); and dissatisfaction was defined as the total score calculated for service users' feelings of satisfaction with the mental health care services that they received (measured using CSQ-8).

Level 2 Variables (Ward Level)

1. Nurses' characteristics included age, gender, nationality, qualifications, years of experience in the hospital, attendance of psychiatric training courses, and staff numbers. Each parameter was treated as an aggregated group value by deriving a new variable that summarized the information as the average (mean) of a continuous variable (i.e., age and staff numbers), and percentage summarizing information on the categorical variables, including gender, nationality, qualifications, years of experience in the hospital, and attendance of psychiatric training courses.
2. The process variables included nurses' attitudes towards the mentally ill/mental illness, nurses' competency in the delivery of mental health care, and the frequency, nature, and characteristics of staff-service user interactions, treated as independent continuous variables, in the form of aggregated group values by deriving a new variable that summarized the information as the average (mean). Thus, the mean score for attitude was calculated from nurses' perceptions of the mentally ill/mental illness in each ward (measured using the ATAMH-33), while the mean competency score was calculated from nurses' levels of competency in the delivery of mental health care on each ward (measured using the CAT-MH), and the mean score for staff-service user interaction was calculated as the number of times that staff interacted with service users in each ward (measured using the IOC).

A detailed view of the dataset analysis, containing service userlevel variables with a ward identifier and 11 ward-level variables, is as follows:

\begin{tabular}{|c|c|}
\hline Variables & Description \\
\hline NURSEAGE & Mean age of nurses (in years) \\
\hline NURSEMALE & Proportion of male nurses, summarized as gender \\
\hline NURSESAUDI & Percentage of Saudi nurses, summarized as nationality \\
\hline NURSEDIPLOMA & $\begin{array}{l}\text { Percentage of nurses who hold a diploma, summarized } \\
\text { as qualifications }\end{array}$ \\
\hline NURSEEXPER & $\begin{array}{l}\text { Proportion of nurses with over } 4 \text { years' experience, } \\
\text { summarized as years of experience in the hospital }\end{array}$ \\
\hline NURSETRAIN & $\begin{array}{l}\text { Percentage of nurses receiving training, summarized } \\
\text { as attendance of psychiatric training courses }\end{array}$ \\
\hline NURSENO & $\begin{array}{l}\text { Staff numbers on the wards }(\mathrm{M} 1=15, \mathrm{M} 2=11, \mathrm{M} 4= \\
13, \mathrm{M} 5=12, \mathrm{M} 6=12, \mathrm{M} 8=10, \mathrm{M} 13=15, \mathrm{M} 14=15 \\
\mathrm{M} 15=12, \mathrm{M} 16=14, \mathrm{M} 17=10, \mathrm{~F} 2=12, \mathrm{~F} 3=14 \text {, and } \\
\mathrm{F} 5=11)\end{array}$ \\
\hline NURSEATTIT & $\begin{array}{l}\text { Mean attitude score calculated from nurses' } \\
\text { perceptions of the mentally ill/mental illness in each } \\
\text { ward, as measured by the ATAMH-33 }\end{array}$ \\
\hline NURSECOMPET & $\begin{array}{l}\text { Mean competency score calculated from nurses' levels } \\
\text { of competency in the delivery of mental health care in } \\
\text { each ward, as measured by the amended CAT-MH }\end{array}$ \\
\hline NURSEINTERAC & $\begin{array}{l}\text { Mean staff-service user interaction score calculated as } \\
\text { the number of times that staff interacted with service } \\
\text { users on each ward, as measured by IOC }\end{array}$ \\
\hline WARDID & Anonymized ward identifier (coded from 1 to 14 ) \\
\hline PTNO & $\begin{array}{l}\text { Number of service users on the ward }(\mathrm{M} 1=24, \mathrm{M} 2= \\
28, \mathrm{M} 4=4, \mathrm{M} 5=3, \mathrm{M} 6=17, \mathrm{M} 8=9, \mathrm{M} 13=74, \\
\mathrm{M} 14=54, \mathrm{M} 15=39, \mathrm{M} 16=14, \mathrm{M} 17=9, \mathrm{~F} 2=32, \\
\mathrm{~F} 3=4, \text { and } \mathrm{F} 5=2)\end{array}$ \\
\hline PTAGE & Age of service user (in years) \\
\hline PTGEN & Gender of service user $\left(1=\right.$ male, ${ }^{\star} 2=$ female $)$ \\
\hline PTMSTATUS & $\begin{array}{l}\text { Marital status of service user (coded } 1 \text { for single, }{ }^{*} 2 \text { for } \\
\text { married, } 3 \text { for divorced, and } 4 \text { for widowed) }\end{array}$ \\
\hline
\end{tabular}

Quality of Mental Health Care and Service Users' Outcomes

\begin{tabular}{|c|c|}
\hline Variables & Description \\
\hline PTESTATUS & $\begin{array}{l}\text { Employment status of service user (coded } 1 \text { for retired, } \\
2 \text { for employed, }{ }^{*} \text { and } 3 \text { for unemployed) }\end{array}$ \\
\hline PTEDUC & $\begin{array}{l}\text { Educational level of service user (coded } 1 \text { for } \\
\text { illiterate, }{ }^{\star} 2 \text { for primary school, } 3 \text { for intermediate } \\
\text { school, } 4 \text { for secondary school, } 5 \text { for college [diploma], } \\
6 \text { for graduate, and } 7 \text { for postgraduate) }\end{array}$ \\
\hline PTAREA & $\begin{array}{l}\text { Area of residence, defined as geographical accessibility } \\
\text { of the hospital to the service users (coded } 1 \text { for western } \\
\text { region, } 2 \text { for eastern region, } 3 \text { for central region, } 4 \text { for } \\
\text { northern region, }{ }^{*} \text { and } 5 \text { for southern region) }\end{array}$ \\
\hline PTDX & $\begin{array}{l}\text { Service user's disease diagnosis (coded } 1 \text { for } \\
\text { schizophrenia, } 2 \text { for personality disorder, } * 3 \text { for } \\
\text { bipolar disorder, } 4 \text { for substance-related disorder, and } \\
5 \text { for depression) }\end{array}$ \\
\hline TOTALSFS & $\begin{array}{l}\text { Total score calculated as the psychiatric service user's } \\
\text { ability to perform necessary social activities, as } \\
\text { measured using the SFS, with a higher score indicating } \\
\text { a higher level of social functioning }\end{array}$ \\
\hline TOTALBPRS & $\begin{array}{l}\text { Total score calculated from specific symptoms of } \\
\text { psychiatric service users, based on service user self- } \\
\text { reporting, as measured by the BPRS. Scores range } \\
\text { from } 0 \text { to } 126 \text {, with a score of over } 68 \text { indicating severe } \\
\text { illness }\end{array}$ \\
\hline TOTALGASS & $\begin{array}{l}\text { Total score calculated as service users' experience of } \\
\text { the side effects of psychiatric medication, as measured } \\
\text { by GASS. Scores range from } 0 \text { to } 66 \text {, with scores over } \\
26 \text { indicating severe side effects }\end{array}$ \\
\hline TOTALCSQ & $\begin{array}{l}\text { Total score calculated as service users' feelings of } \\
\text { satisfaction with the mental health care services } \\
\text { received, as measured by CSQ- } 8 \text {. Scores range from } \\
8 \text { to 32, with the highest score indicating greater } \\
\text { satisfaction }\end{array}$ \\
\hline
\end{tabular}

$\mathrm{M}$, male ward; $F$, female ward. ${ }^{*}$ Set as the reference category in all the analysis models; each category of predictors was contrasted with the reference category. 
Table 1. Results of multilevel modelling investigating predictors of service users' social functioning status, as measured by the SFS

\begin{tabular}{|c|c|c|c|c|}
\hline Variables & Coefficient & SE & $p$ value & $R^{2}$ \\
\hline (Constant) & 97.565 & 5.076 & 0.000 & \\
\hline Age & -0.500 & 0.170 & $0.003^{* *}$ & $2.3 \%$ \\
\hline \multicolumn{5}{|l|}{ Gender } \\
\hline Male (reference) & & & & $0.001 \%$ \\
\hline Female & 1.243 & 13.333 & 0.926 & \\
\hline \multicolumn{5}{|l|}{ Marital status } \\
\hline \multicolumn{5}{|l|}{ Single (reference) } \\
\hline Married & 12.417 & 4.158 & $0.003^{\star \star}$ & $4.2 \%$ \\
\hline Divorced & -3.583 & 4.837 & 0.459 & \\
\hline Widowed & -20.628 & 10.910 & 0.059 & \\
\hline \multicolumn{5}{|l|}{ Employment status } \\
\hline Employed (reference) & & & & $4.2 \%$ \\
\hline Retired & -11.575 & 6.126 & 0.059 & \\
\hline Unemployed & -17.267 & 4.480 & $0.000^{* *}$ & \\
\hline \multicolumn{5}{|l|}{ Educational level } \\
\hline Illiterate (reference) & & & & $5.4 \%$ \\
\hline Primary school & 12.926 & 7.236 & 0.074 & \\
\hline Intermediate school & 20.507 & 7.250 & $0.005^{\star *}$ & \\
\hline Secondary level & 21.922 & 7.291 & $0.003^{\star *}$ & \\
\hline College & 17.039 & 9.190 & 0.064 & \\
\hline Graduate & 29.822 & 8.582 & $0.001^{\star *}$ & \\
\hline Postgraduate & 46.399 & 17.452 & $0.008^{\star *}$ & \\
\hline \multicolumn{5}{|l|}{ Area of residence } \\
\hline North region (reference) & & & & $3.7 \%$ \\
\hline Western region & -23.302 & 14.247 & 0.102 & \\
\hline Eastern region & -53.442 & 20.147 & $0.008^{\star *}$ & \\
\hline Central region & -30.149 & 14.941 & $0.044^{\star}$ & \\
\hline South region & -39.301 & 15.985 & $0.014^{\star}$ & \\
\hline \multicolumn{5}{|l|}{ Diagnosis } \\
\hline Personality disorder (reference) & & & & $3.4 \%$ \\
\hline Schizophrenia & -23.188 & 8.762 & $0.008^{\star *}$ & \\
\hline Bipolar disorder & -18.643 & 10.587 & 0.078 & \\
\hline Substance-related disorder & -10.139 & 10.011 & 0.311 & \\
\hline Depression & -26.242 & 13.033 & $0.044^{*}$ & \\
\hline
\end{tabular}

SFS, Social Functioning Scale; SE, standard error of the estimated coefficient; $R^{2}$, coefficient of determination or variance explained. ${ }^{*} p<0.05 .{ }^{*} p<0.01$.

Complete Removal of All Staff (Except Nurses) and Admission Ward Data from the Final Data Analysis

Although the lead researcher had collected data from all staff (psychiatrists, psychologists, nurses, social workers, and occupational therapists) and ward sources, we found that data gathered from other professionals could not be reasonably matched to participant outcomes. This is because, unlike nurses, other staff did not have 24-h involvement in patient care. As a result, there was the possibility of making spurious associations, especially when using SPSS software. The removal of these data and use of MLwiN software considerably reduced the possibility of such bias and minimized the likelihood of detecting spurious associations.

\section{Results}

\section{Sample Characteristics}

The sample of nurses consisted of 176 (76.5\% response rate), aged between 23 and 60 years (mean $=31.49, \mathrm{SD}=$ $6.094)$. Among these, $64.8 \%(n=114)$ were male and $35.2 \%(n=62)$ were female. Over two-thirds of the participants $(n=135,76.7 \%)$ were Saudi, while $23.3 \%(n=$ $41)$ were non-Saudi. The majority of the sample held a diploma $(n=146,83 \%)$. One hundred and twenty $(68.2 \%)$ participants had over 4 years' experience in the field of 
Table 2. Results of multilevel modelling investigating predictors of service users' symptoms, as measured by the BPRS

\begin{tabular}{|c|c|c|c|c|}
\hline Variables & Coefficient & SE & $p$ value & $R^{2}$ \\
\hline (Constant) & 1.592 & 0.010 & 0.000 & \\
\hline Age & 0.000 & 0.001 & 0.670 & $0.0 \%$ \\
\hline \multicolumn{5}{|l|}{ Gender } \\
\hline Male (reference) & & & & $0.0 \%$ \\
\hline Female & 0.010 & 0.028 & 0.717 & \\
\hline \multicolumn{5}{|l|}{ Marital status } \\
\hline Single (reference) & & & & $5.6 \%$ \\
\hline Married & 0.002 & 0.019 & 0.921 & \\
\hline Divorced & 0.042 & 0.022 & 0.057 & \\
\hline Widowed & 0.025 & 0.051 & 0.623 & \\
\hline \multicolumn{5}{|l|}{ Employment status } \\
\hline Employed (reference) & & & & $5.6 \%$ \\
\hline Retired & 0.027 & 0.028 & 0.339 & \\
\hline Unemployed & 0.051 & 0.021 & $0.014^{*}$ & \\
\hline \multicolumn{5}{|l|}{ Educational level } \\
\hline Illiterate (reference) & & & & $5.6 \%$ \\
\hline Primary school & -0.016 & 0.034 & 0.636 & \\
\hline Intermediate school & -0.028 & 0.033 & 0.401 & \\
\hline Secondary level & -0.004 & 0.034 & 0.908 & \\
\hline College & -0.026 & 0.043 & 0.549 & \\
\hline Graduate & -0.028 & 0.040 & 0.477 & \\
\hline Postgraduate & -0.030 & 0.082 & 0.713 & \\
\hline \multicolumn{5}{|l|}{ Area of residence } \\
\hline North region (reference) & & & & $5.6 \%$ \\
\hline Western region & 0.023 & 0.067 & 0.727 & \\
\hline Eastern region & 0.117 & 0.094 & 0.211 & \\
\hline Central region & 0.004 & 0.070 & 0.950 & \\
\hline South region & -0.001 & 0.075 & 0.985 & \\
\hline \multicolumn{5}{|l|}{ Diagnosis } \\
\hline Personality disorder (Reference) & & & & $5.6 \%$ \\
\hline Schizophrenia & 0.068 & 0.041 & 0.096 & \\
\hline Bipolar disorder & 0.024 & 0.049 & 0.619 & \\
\hline Substance-related disorder & 0.026 & 0.046 & 0.573 & \\
\hline Depression & 0.089 & 0.060 & 0.136 & \\
\hline
\end{tabular}

BPRS, Brief Psychiatric Rating Scale; SE, standard error of the estimated coefficient; $R^{2}$, coefficient of determination or variance explained. ${ }^{\star} p<0.05$.

mental health. Out of all the participants, $88.6 \%(n=156)$ had attended specialized training and educational courses in mental health.

The sample of service users consisted of 321 (62.1\% response rate), aged between 18 and 69 years, with a mean of 39.02 ( $\mathrm{SD}=11.33$ ) years: 283 being male $(88.2 \%)$ and 38 female $(11.8 \%)$. Over half the sample were single $(64.8 \%)$ and most were educated $(93.8 \%)$ and living in the western region of the KSA (81.9\%). The majority were unemployed $(71 \%)$, and $75.7 \%$ were diagnosed with schizophrenia.

Quality of Mental Health Care and Service Users' Outcomes

\section{Service Users' Characteristics and Outcomes}

Multilevel modelling (regression model) was run to predict the outcomes for service users' age, gender, marital status, employment status, educational level, area of residence, and diagnosis (level 1 variables). Table 1 shows that age of the service user was a significant predictor of SFS and explained $2.3 \%$ of variance (Coef $=0.500, p=0.003$ ). However, gender did not significantly predict SFS (Coef $=1.243$, $p=0.926)$. In terms of marital status, being married was a significant predictor of the SFS score and explained $4.2 \%$ of variance (Coef $=12.417, p=0.003)$. Of the employment sta- 
Table 3. Results of multilevel modelling investigating predictors of service users' side effects, as measured by the GASS

\begin{tabular}{|c|c|c|c|c|}
\hline Variables & Coefficient & $\mathrm{SE}$ & $p$ value & $R^{2}$ \\
\hline (Constant) & 3.007 & 0.141 & 0.000 & \\
\hline Age & -0.006 & 0.009 & 0.524 & $0.1 \%$ \\
\hline \multicolumn{5}{|l|}{ Gender } \\
\hline Male (reference) & & & & $0.1 \%$ \\
\hline Female & 0.362 & 0.390 & 0.353 & \\
\hline \multicolumn{5}{|l|}{ Marital status } \\
\hline Single (reference) & & & & $0.9 \%$ \\
\hline Married & 0.189 & 0.236 & 0.423 & \\
\hline Divorced & 0.341 & 0.270 & 0.208 & \\
\hline Widowed & 0.681 & 0.617 & 0.270 & \\
\hline \multicolumn{5}{|l|}{ Employment status } \\
\hline Employed (reference) & & & & $0.3 \%$ \\
\hline Retired & -0.114 & 0.345 & 0.741 & \\
\hline Unemployed & -0.202 & 0.253 & 0.425 & \\
\hline \multicolumn{5}{|l|}{ Educational level } \\
\hline Illiterate (reference) & & & & $3.0 \%$ \\
\hline Primary school & 0.667 & 0.405 & 0.100 & \\
\hline Intermediate school & 0.981 & 0.402 & $0.015^{\star}$ & \\
\hline Secondary level & 0.683 & 0.406 & 0.092 & \\
\hline College & 1.233 & 0.515 & $0.017^{\star}$ & \\
\hline Graduate & 0.983 & 0.480 & $0.041^{\star}$ & \\
\hline Postgraduate & 0.417 & 0.987 & 0.673 & \\
\hline \multicolumn{5}{|l|}{ Area of residence } \\
\hline North region (reference) & & & & $3.5 \%$ \\
\hline Western region & 1.541 & 0.798 & 0.054 & \\
\hline Eastern region & 1.595 & 1.123 & 0.155 & \\
\hline Central region & 0.885 & 0.836 & 0.290 & \\
\hline South region & 0.894 & 0.894 & 0.317 & \\
\hline \multicolumn{5}{|l|}{ Diagnosis } \\
\hline Personality disorder (reference) & & & & $0.5 \%$ \\
\hline Schizophrenia & 0.139 & 0.497 & 0.779 & \\
\hline Bipolar disorder & 0.479 & 0.600 & 0.425 & \\
\hline Substance-related disorder & -0.136 & 0.567 & 0.811 & \\
\hline Depression & 0.121 & 0.733 & 0.869 & \\
\hline
\end{tabular}

GASS, Glasgow Antipsychotic Side-effect Scale; SE, standard error of the estimated coefficient; $R^{2}$, coefficient of determination or variance explained. ${ }^{\star} p<0.05$.

tus variables, unemployment was a significant predictor of SFS and explained $4.2 \%$ of variance (Coef $=17.267, p=$ $0.000)$. Nevertheless, service users' level of education was a significant predictor of SFS ( $p=0.005, p=0.003, p=0.001$, and $p=0.008$, respectively), explaining $5.4 \%$ of variance. Moreover, the area of the service user's residence was a significant predictor of the total SFS score and explained 3.7\% of variance. Finally, the diagnosis of schizophrenia or depression was another significant predictor of the total SFS score $($ Coef $=23.188, p=0.008$; Coef $=26.242, p=0.044$, respectively), explaining $3.4 \%$ of variance.
Except for the unemployment variable, none of the variables of service users' characteristics were found to be a statistically significant predictor of BPRS among the service users, explaining $5.6 \%$ of variance (Coef $=0.051$, $p=0.014$ ) (Table 2). Only the service users' level of education was indicated as a significant predictor of either total GASS score, explaining 3\% of variance $(p=0.015$, $p=0.017$, and $p=0.041$, respectively) (Table 3 ), or total CSQ-8 score (Coef $=0.958, p=0.001)$, explaining $8.9 \%$ of variance (Table 4$)$. 
Table 4. Results of multilevel modelling investigating predictors of service users' satisfaction with health care services, as measured by the CSQ-8

\begin{tabular}{|c|c|c|c|c|}
\hline Variables & Coefficient & SE & $p$ value & $R^{2}$ \\
\hline (Constant) & 3.035 & 0.070 & 0.000 & \\
\hline Age & -0.006 & 0.005 & 0.230 & $0.9 \%$ \\
\hline \multicolumn{5}{|l|}{ Gender } \\
\hline Male (reference) & & & & $0.2 \%$ \\
\hline Female & -0.269 & 0.193 & 0.162 & \\
\hline \multicolumn{5}{|l|}{ Marital status } \\
\hline Single (reference) & & & & $0.4 \%$ \\
\hline Married & -0.161 & 0.141 & 0.253 & \\
\hline Divorced & 0.067 & 0.160 & 0.676 & \\
\hline Widowed & -0.223 & 0.370 & 0.547 & \\
\hline \multicolumn{5}{|l|}{ Employment status } \\
\hline Employed (reference) & & & & $0.3 \%$ \\
\hline Retired & -0.133 & 0.205 & 0.517 & \\
\hline Unemployed & -0.005 & 0.150 & 0.972 & \\
\hline \multicolumn{5}{|l|}{ Educational level } \\
\hline Illiterate (reference) & & & & $8.9 \%$ \\
\hline Primary school & -0.070 & 0.234 & 0.765 & \\
\hline Intermediate school & 0.221 & 0.232 & 0.341 & \\
\hline Secondary level & 0.278 & 0.234 & 0.236 & \\
\hline College & 0.584 & 0.298 & 0.050 & \\
\hline Graduate & 0.958 & 0.277 & $0.001^{*}$ & \\
\hline Postgraduate & 0.689 & 0.572 & 0.228 & \\
\hline \multicolumn{5}{|l|}{ Area of residence } \\
\hline North region (reference) & & & & $0.5 \%$ \\
\hline Western region & -0.272 & 0.484 & 0.574 & \\
\hline Eastern region & 0.291 & 0.680 & 0.669 & \\
\hline Central region & -0.231 & 0.507 & 0.649 & \\
\hline South region & -0.301 & 0.542 & 0.578 & \\
\hline \multicolumn{5}{|l|}{ Diagnosis } \\
\hline Personality disorder (reference) & & & & $1.2 \%$ \\
\hline Schizophrenia & -0.326 & 0.296 & 0.271 & \\
\hline Bipolar disorder & -0.684 & 0.356 & 0.055 & \\
\hline Substance-related disorder & -0.231 & 0.337 & 0.493 & \\
\hline Depression & -0.494 & 0.434 & 0.254 & \\
\hline
\end{tabular}

CSQ-8, Client Satisfaction Questionnaire; SE, standard error of the estimated coefficient; $R^{2}$, coefficient of determination or variance explained. ${ }^{\star} p<0.01$.

\section{Staffs' Characteristics and Service Users' Outcomes}

The staff characteristics contained 7 ward-level variables (i.e., age, gender, nationality, qualifications, years of experience in the hospital, attendance of psychiatric training courses, and staff numbers), which were potential predictors of outcomes. Each variable was added to the multilevel modelling in a sequential manner, 1 variable at a time.

Both nurses' age, measured at ward-level as a mean age score, and years of experience of working in the hospital proved to be significant predictors of SFS (Coef $=5.024$, $p=0.002$, explaining $47.9 \%$ of variance; Coef $=0.887, p=$ 0.004 , explaining $44.3 \%$ of variance, respectively) (Ta- ble 5), with the number of years of experience in the hospital being the only significant predictor of dissatisfaction (CSQ-8) (Coef $=0.009, p=0.028)$, explaining $100 \%$ of variance (Table 6). However, no nurses' characteristics were indicated as statistically significant predictors of service users' outcomes, in terms of either BPRS or GASS (online suppl. Tables 2, 3, respectively).

\section{Staffs' Attitudes, Competence, and Staff-Service User}

Interaction, and Service Users' Outcomes

The outcome variables were added separately to the multilevel modelling. Nurses' attitudes towards the mentally ill/ 
Table 5. Results of multilevel modelling investigating predictors of SFS from nurses' characteristics

\begin{tabular}{|c|c|c|c|c|c|}
\hline \multirow[t]{2}{*}{ Variables } & \multirow[t]{2}{*}{ Coefficient } & \multirow[t]{2}{*}{ SE } & \multirow[t]{2}{*}{$p$ value } & \multicolumn{2}{|l|}{$R^{2}$} \\
\hline & & & & $\mathrm{L} 2$ & $\mathrm{~L} 1$ \\
\hline (Constant) & 97.565 & 5.076 & 0.000 & & \\
\hline Age & -5.024 & 1.653 & $0.002^{*}$ & $47.9 \%$ & $0.3 \%$ \\
\hline Gender & -14.469 & 10.996 & 0.188 & $8.6 \%$ & $0.2 \%$ \\
\hline Nationality & 0.231 & 0.144 & 0.109 & $11.8 \%$ & $0.4 \%$ \\
\hline Qualifications & 0.268 & 0.197 & 0.173 & $7.6 \%$ & $0.3 \%$ \\
\hline Years of experience in the hospital & -0.887 & 0.306 & $0.004^{*}$ & $44.3 \%$ & $0.4 \%$ \\
\hline Attendance of psychiatric training courses & -0.052 & 0.458 & 0.910 & $0.6 \%$ & $0.0 \%$ \\
\hline Staff numbers & 2.008 & 2.796 & 0.473 & $6.8 \%$ & $0.0 \%$ \\
\hline
\end{tabular}

SFS, Social Functioning Scale; SE, standard error of the estimated coefficient; $R^{2}$, coefficient of determination or variance explained; L2, level 2 (between-ward variance); L1, level 1 (within-ward variance). ${ }^{*} p<0.01$.

Table 6. Results of multilevel modelling investigating predictors of CSQ-8 scores for nurses' characteristics

\begin{tabular}{lccccc}
\hline Variables & Coefficient & SE & $p$ value & \multicolumn{2}{c}{$R^{2}$} \\
\cline { 4 - 7 } & & & & L2 & L1 \\
\hline (Constant) & & & & & \\
Age & -0.005 & 0.038 & 0.889 & $0.0 \%$ & $0.1 \%$ \\
Gender & -0.306 & 0.176 & 0.083 & $35.3 \%$ & $0.5 \%$ \\
Nationality & 0.004 & 0.002 & 0.091 & $35.3 \%$ & $0.5 \%$ \\
Qualifications & 0.005 & 0.003 & 0.076 & $52.9 \%$ & $0.3 \%$ \\
Years of experience in the hospital & 0.009 & 0.004 & $0.028^{*}$ & $100 \%$ & $0.0 \%$ \\
Attendance of psychiatric training courses & 0.010 & 0.006 & 0.071 & $76.5 \%$ & $0.0 \%$ \\
Staff numbers & -0.042 & 0.035 & 0.233 & $58.8 \%$ & $0.0 \%$ \\
\hline
\end{tabular}

CSQ-8, Client Satisfaction Questionnaire; SE, standard error of the estimated coefficient; $R^{2}$, coefficient of determination or variance explained; L2, level 2 (between-ward variance); L1, level 1 (within-ward variance). $* p<0.05$.

mental illness, measured at ward level as a mean of the attitude score, did not significantly predict service users' outcomes, SFS, BPRS, GASS, and CSQ-8 ( $p=0.057, p=0.220$, $p=0.082$, and $p=0.397$, respectively) (online suppl. Table 4 ). However, nurses' competence, measured at ward level as a mean competence score, was revealed as a statistically significant predictor of SFS scores (Coef $=1.501, p=0.000)$ and explained $56.5 \%$ of variance. Meanwhile, none of the other variables for service users' outcomes (BPRS, GASS, and CSQ8 ) were predicted by nurses' competence in the delivery of mental health care $(p=0.860, p=0.644$, and $p=0.787$, respectively) (Table 7). Moreover, the frequency and nature of staff-service user interaction was not a statistically significant predictor of any measures of service users' outcomes: SFS, BPRS, GASS, and CSQ-8 ( $p=0.631, p=0.396, p=0.748$, and $p=0.201$, respectively) (online suppl. Table 5).

\section{Discussion}

The authors investigated the structure and process factors associated with the quality of mental health care captured by measures of service users' disability, discomfort, disease, and dissatisfaction in the KSA.

\section{Service Users' Characteristics and Outcomes}

The present study showed a significant negative predictor of psychiatric disability in relation to service user age. Our data suggested that the older the service user, the less capable they were in engaging in social activities. The finding was consistent with that of Unick et al. [26] who reported service users who consume a disproportionate share of services were significantly more likely to belong to the younger age. Similarly, Morris et al. [27] reported 
Table 7. Results of multilevel modelling investigating predictors of service users' outcomes from nurses' competence

\begin{tabular}{lccccc}
\hline & \multicolumn{2}{l}{ Nurses' competence (CAT-MH) } & & & \\
\cline { 2 - 6 } & Coefficient & SE & p value & $R^{2}$ & \\
\cline { 3 - 7 } & & & & L2 & L1 \\
\hline (Constant) & 97.565 & 5.076 & 0.000 & & \\
Disability (SFS) & -1.501 & 0.412 & $0.000^{*}$ & $56.5 \%$ & $0.72 \%$ \\
(Constant) & 1.592 & 0.010 & 0.000 & & \\
Disease (BPRS) & 0.000 & 0.001 & 0.860 & $0.0 \%$ & $0.0 \%$ \\
(Constant) & 3.007 & 0.141 & 0.000 & & \\
Discomfort (GASS) & -0.008 & 0.016 & 0.644 & $0.91 \%$ & $0.04 \%$ \\
(Constant) & 3.035 & 0.070 & 0.000 & & \\
Dissatisfaction (CSQ-8) & -0.002 & 0.009 & 0.787 & $0.0 \%$ & $0.11 \%$ \\
\hline
\end{tabular}

CAT-MH, Competency Assessment Tool-Mental Health; SE, standard error of the estimated coefficient; $R^{2}$, coefficient of determination or variance explained; L2, level 2 (between-ward variance); L1, = level 1 (within-ward variance); BPRS, Brief Psychiatric Rating Scale; GASS, Glasgow Antipsychotic Side-Effect Scale; CSQ-8, Client Satisfaction Questionnaire. ${ }^{*} p<0.01$.

that the fact of being older, female, from an ethnic minority, and having a diagnosis of schizophrenia, all predicted poorer outcomes among service users.

Being married was a further significant predictor of social functioning. In this study, $19 \%$ of the participants reported being married, with a significantly higher number of participants in admission wards reporting that they were married, compared with participants in other wards. Married participants tend to face their mental disorders positively by accessing appropriate social support or through social integration. This finding is consistent with a study conducted by Akinsulore et al. [28] who found that marital status was a significant predictor of the disability score.

We also found unemployment status as another significant predictor and negatively related to disability. In sum, the result suggests that unemployed service users have lower levels of social functioning, as unemployment predicted a lower social functioning status among the service users in the present study. This may relate to a number of different factors, including the fact that $75.7 \%$ of the sample were diagnosed with schizophrenia, since the participants diagnosed with schizophrenia tended to report greater impairment in their social functioning status, as well as a secondary disability (less active pursuit of work) [29]. Approximately $71 \%$ of the participants were out of work, with percentage of unemployment being high across all the admission wards, compared to other categories of employment status (retired or employed).
This current finding is consistent with those of previous studies, where it has been revealed that prolonged periods of unemployment were inversely correlated with mental well-being and psychological functioning [30]. In contrast, employment is regarded as personally satisfying and those capable of remaining in employment may have more effective coping mechanisms, enabling them to deal with associated difficulties, such as psychological and social relationships, and other therapeutic considerations [31].

Our findings also revealed service users' level of education as another significant predictor of social functioning. This result implies that individuals with a higher level of education are more likely to use care services. For instance, the use of mental health services, as well as social functioning (e.g., care-seeking), may be influenced by conventional quality indicators, such as educational level, as demonstrated in previous studies [31, 32]. For example, Razzano et al. [32] found significant positive relationships between the uptake of mental health services and educational level, whereby the number of individuals with a relatively high level of education in the study sample was greater $(93.8 \%)$ than the number of participants with only basic literacy. This was attributed to the phenomenon of individuals with a higher level of formal education being more likely than those with a lower level of education to seek care. It is a finding that may be associated with the view that participants who are not so welleducated are more likely to suffer the cognitive problems 
that are frequently observed among service users with mental disorders, particularly schizophrenia.

Area of service users' residence (eastern region, central region, and south region) was also found a predictor and negatively related to their social functioning. The association between area of residence and social functioning status has rarely been addressed, but the present study is inconsistent with prior research in finding area of residence to be an enabling variable (living in an urban area), with a significant impact on service utilization. Therefore, service users living in urban areas had access to fewer services than service users living in non-urban areas [33].

Service users' diagnoses (schizophrenia and depression) were also among the significant predictors of social functioning. These results suggest that social functioning is significant for mitigating disease and is therefore of great importance for service users with mental disorders, particularly schizophrenia and depression. In line with other Western studies [34], schizophrenia was the most frequent diagnosis among the participants in this study, accounting for $75.7 \%$ of all the service users. Impairment of social functioning is regarded as one of the hallmarks of individuals diagnosed with schizophrenia [35]. In addition, deterioration of social performance is one of the defining diagnostic criteria specified in $D S M-V$ [11], and social impairments, such as social withdrawal, were listed as residual symptoms affecting individuals' life-role functioning, such as everyday life skills. This result correlates well with a study by Chudleigh et al. [35] who found that increased levels of depressive symptoms were correlated with decreased levels of social functioning (i.e., withdrawal/social engagement, interpersonal communication, and getting along with people).

Moreover, deterioration of social performance is one of the defining diagnostic criteria specified in DSM-V [11], and social impairments, such as social withdrawal, were listed as residual symptoms affecting individuals' life-role functioning, such as everyday life skills. This result is in accordance with another study [35], where increased levels of depressive symptoms correlated with decreased levels of social functioning (i.e., withdrawal/social engagement, interpersonal communication, and getting along with people).

With regard to service users' characteristics and disease, unemployment displayed a significant predictor of the severity of psychiatric symptoms. Arguably, unemployed service users were more likely than employed service users to complain of certain psychiatric symptoms. It is possible that the employed service users had superior coping strategies, compared to their unemployed counterparts. Therefore, it could be argued that the use of practical coping strategies or skills at work served to strengthen them. This result was consistent with previous research reporting that employed service users enjoy better mental health than, for example, their unemployed counterparts, service users on sick leave, or service users on disability pensions [36]. A similar finding was published by McGurk and Meltzer [37], reporting that service users who were employed full-time were more likely to be treated with antipsychotic medication, had more positive symptoms, and were engaged in more cognitively complex work tasks than part-time employed and unemployed service users.

In terms of service users' characteristics and discomfort, educational level (intermediate, college, or graduate) showed a significant predictor of the side effects of psychiatric medication. This finding suggested that educated service users, irrespective of their level of education, were more likely to report fewer side effects. This is in line with the findings of previous research conducted by Seltzer et al. [38], who reported that educated service users were more likely to be compliant in outpatient follow-up and were less fearful of the side effects of prescribed psychiatric medication or of the risk of addiction.

With regard to service users' characteristics and dissatisfaction, education displayed a significant predictor of service users' satisfaction. Thus, service users who were university graduates were more likely to report satisfaction with care services. This finding implies that service users with higher levels of education were more likely to be satisfied with their hospital care. In line with our findings, a study in Qatar also showed that service users of low socio-economic status and with a low level of education tended to be less satisfied with mental health care services [39]. In contrast to a prior study [40], formal education has no clear association with service users' satisfaction with various aspects of their care. However, these outcomes may be attributed to a number of methodological issues in studies on service user satisfaction, including the use of non-standardized instruments and the evaluation of performance in experimental, rather than actual psychiatric services [41].

\section{Staffs' Characteristics and Service Users' Outcomes}

Our findings showed that the nursing staff's age and years of experience in the hospital were negatively predicted social functioning. This finding suggested that the less professional experience a nurse had of working at the hospital, the less skilled he or she was in coping with dis-
Al Mousa/Callaghan/Michail 
abled service users. Health-care professionals, such as nurses, have frequent contact with service users, but to the best of the authors' knowledge, studies investigating nurses' characteristics, including age and experience, are rare (especially in the field of mental health) and even those that exist reveal very little about the relationship with service users' outcomes. For example, studies investigating nurses' socio-demographic characteristics, such as age and gender, have been conducted, but they are linked with findings other than service users' outcomes, such as staff attitudes and turnover.

It may be reasonable to suggest here that the level of a service user's social functioning may be associated with better nursing care performance. In turn, this could have a beneficial effect on service users' outcomes overall. In a Canadian study, Doran et al. [42] assessed social functioning, using an instrument that they had developed themselves. It contained 4 items to measure service users' readiness to resume work, usually physical and social activities, using a 4-point Likert scale. The study demonstrated that the level of nurses' performance was associated with better social functioning among service users and less mood disturbance on discharge from hospital. Generally speaking, the greater the professional experience displayed by a member of staff, in terms of knowledge and skills, the more confident he or she is likely to be in providing effective health care and, more importantly, improving service users' outcomes, including social functioning [43].

\section{Staffs' Competence and Service Users' Outcomes}

We found a statistically significant negative prediction of social functioning based on nurses' competence, which can be explained by the fact that lower levels of competence and a lack of experience among staff result in poorer social relationships with service users and low performance of daily activities. It is a finding that shows how staff competence may be regarded as an indicator of poor quality of support for the social functioning of service users. In the context of the current study, it could equally be argued that social functioning is important for service users, not only to ensure that they are discharged from hospital with a more positive experience of care but also that they possess the necessary skills for independent living. The service users' sense of being "disabled" may even develop from an absence of appropriate support during hospitalization. However, there is a lack of studies investigating the relationship between the competence of nursing staff and service users' social functioning in mental health and community settings. Future studies are therefore re- quired around outcome measures, such as social functioning and staff competence.

Nevertheless, the nature of the participating nurses could explain the present findings. First, the level of nurses' competence in the delivery of mental health care in the inpatient wards (as measured using CAT$\mathrm{MH}$ ) was revealed as "moderate" (mean $=86.40)$, indicating that the nurses required some form of participation in intensive courses (e.g., in psychosocial care), so that they could develop skills and knowledge in aspects of mental health care. Second, the nurses' educational qualifications were found to vary in level, with the majority of the sample only holding a nursing diploma $(83 \%)$, possibly indicating that the majority of nurses working in the field of mental health are less qualified than one would generally expect, and this potentially has an adverse effect on service users' outcomes. Finally, only $68.2 \%$ of the nurses had over 4 years' experience in the field of psychiatry, which illustrates that a considerable number of the participating nurses (31.8\%) still had relatively low levels of professional experience in the field (less than 4 years). Hence, they may have been less capable of providing competent nursing care, which could impact service users' outcomes in negative ways.

However, it is important and interesting to note that the WHO and GCC Nursing Technical Committee support the requirement of a bachelor's degree in nursing as the minimum entry requirement for the nursing profession [44]. In the KSA, this means a 5-year university course, which is a positive step towards developing the quality of nursing care [44]. Therefore, it could be stated that an increased emphasis on bachelor's degrees for nurses will improve service users' outcomes. There is in fact growing evidence that a bachelor's degree in nursing is associated with better care outcomes, such as lower hospital mortality [45]. Further research could therefore be useful for assessing the impact of nurses' education on mental health service users' outcomes, particularly social functioning status.

\section{Staff-Service User Interaction and Service Users' Outcomes}

The results of the present study failed to obtain a statistically significant prediction of service users' outcomes in relation to the frequency and nature of staff-service user interactions, in terms of disability, disease, discomfort, and dissatisfaction. This is in line with the findings of a previous study [46] but not of others [47, 48]. 


\section{Strengths and Limitations}

As far as we are aware, our study is the first study to investigate the issues surrounding QoC using the $5 \mathrm{D}$ approach in a mental health context internationally and in Arabic-speaking countries. This study therefore has the potential to help shape future efforts to improve QoC for users of mental health services, particularly in the KSA. Among the strengths of the study was also that inclusion of participants was not limited to a specific diagnosis, and this inclusiveness may be useful for ensuring that the findings have external validity.

The limitations of the findings must be acknowledged. Although Donabedian's framework appears to be a conceptually sound, practically viable, and empirically grounded model, it produced only very modest results in the current study, and this had not been predicted by testing the model. There were consequently concerns that this model may not have been able to support findings drawn from a population that had not been tested before.

It could thus be stated that this study has revised the Donabedian's model to illustrate how structure, as measured by the staff characteristics sheet (including age, gender, nationality, qualifications, years of experience in the hospital, and attendance of psychiatric training courses) and service user characteristics sheet (including age, gender, marital status, employment status, education level, area of residence, and disease diagnosis), is important in non-Saudi contexts but appears to be less important in the KSA. Thus, while it is valid to consider the use of the model, a very different process is clearly played out in the KSA, compared to other countries. Moreover, limitations include the measure of service users' outcomes (SFS, BPRS, GASS, and CSQ-8). While valid and reliable and used extensively elsewhere, they may lack the sensitivity to measure the same constructs in the Saudi mental health organisations, given its different culture.

Furthermore, it may be concluded that the 5 D's are not necessarily the only issue, since they merely represent broad concepts (a framework). Consequently, the choice of measures for the factors (i.e., structure and process measures) could be the problem in this study; although the sample size is adequate and the measures are valid and reliable. Finally, most of the process and outcome instruments are self-report, and this could have caused response bias.

These findings suggest that factors other than those studied here have more currency in relation to quality of care in Saudi Arabia, despite these factors have been shown to relate to quality of care outside the KSA. A more detailed qualitative approach to better understand factors relevant to the quality of mental care in Saudi Arabia is reported by the authors in a concomitant article. It has been suggested that the themes generated from the qualitative data (5 themes) suggest quality indicators that are perhaps more relevant and need to be tested quantitatively, as proposed in the suggested conceptual model (alternative indicators). They also provide insights regarding predictors of quality underlying the care received in the KSA. It could be argued that the originality of the current study rests upon the fact that this is the first test of these proposed qualitative indicators of quality in an untested context. Thus, future research is required before firm conclusions can be inferred regarding the underlying framework's efficacy and validity, incorporating the themes generated from the qualitative findings (reported by the authors in a concomitant article). This suggests that the service users' perceptions would have a much wider influence than the quantitative data collected, on improving mental health care quality. However, given the positive feedback received from others $[3,4,6-8]$ and the solid inductive base of the framework [1], it is hoped that there is room for optimism.

\section{Relevance for Clinical Practice}

Our findings should be taken into consideration by health-care administrators seeking to improve mental health service users' outcomes. Given the negative perceptions of nurses' educational level, nurses at all levels need to develop reflective knowledge, so that they can support users of mental health services. Therefore, attention must be given to nursing education at undergraduate and graduate levels. Factors such as nurse training programmes, continuing professional development, and ongoing education will help change nurses' negative attitudes, as well as developing their therapeutic abilities. This will likewise enhance their interaction with service users during their stays in hospital [49]. Furthermore, nursing attitudes and behaviours must be addressed and appropriately integrated into the nursing curriculum, in order to reflect national and international standards of mental health care.

\section{Conclusions}

Structure and processes of mental health care in the KSA used in this study had little impact on most service users' outcomes. We have established that factors other than those studied here have more currency in relation to quality of mental health care in the KSA, despite these factors have been shown to relate to QoC in countries other than the KSA.
Al Mousa/Callaghan/Michail 


\section{Acknowledgements}

The authors thank all staff and mental health service users at the hospital involved, especially, Dr. Abbas Hasan and Dr. Jaafer Al Abbad, for translation of the study measures, and Maheswari Sankara Subbu and Rekha Chezhiyan for their assistance in collecting observational data at the study site. Dr. Boliang Guo at the University of Nottingham is thanked for his statistical advice and support.

\section{Statement of Ethics}

Ethics approval was obtained from the University of Nottingham, Faculty of Medicine and Health Sciences Research Ethics Committee (Ref. OVS13022014 SoHS), and the Saudi General Directorate of Research and Studies - MOH and the Institutional Review Board at King Fahad Specialist Hospital - Dammam, KSA (Ref. MOH0170). Participants were given an information sheet explaining the aim of the study, that participation was voluntary, that their responses were confidential, and that the results would be published. No financial payment or incentives were offered for participation. Written consent was obtained from all participants.

\section{Conflict of Interest Statement}

The authors declare no conflicts of interest.

\section{Funding Sources}

This study did not receive any specific grant from funding agencies in the public, commercial, or not-for-profit sectors.

\section{Author Contributions}

The manuscript has been derived from the work associated with a PhD undertaken by $\mathrm{Y}$. Al Mousa. The study was designed by Y. Al Mousa, P. Callaghan, and M. Michail, who also conducted the statistical analysis with guidance from a statistician. Y. Al Mousa wrote the initial draft of the manuscript and all authors contributed to, edited, and approved the final manuscript.

\section{References}

1 Moore L, Lavoie A, Bourgeois G, Lapointe J. Donabedian's structure-process-outcome quality of care model: validation in an integrated trauma system. J Trauma Acute Care Surg. 2015;78(6):1168-75.

2 Attree M. Towards a conceptual model of "quality care". Int J Nurs Stud. 1996;33(1): $13-28$.

3 Ravelli DP, Buwalda VJ, Slooff CJ, Schrijvers AJ, Van Engeland H. Do integrated mental healthcare organisations facilitate process quality in the treatment of people with schizophrenia and related psychoses? Int J Integr Care. 2003;3(1):e17-9.

4 Schröder A, Ahlström G. Psychiatric care staff's and care associates' perceptions of the concept of quality of care: a qualitative study. Scand J Caring Sci. 2004;18(2):204-12.

5 Brown JF. Psychiatric emergency services: a review of the literature and a proposed research agenda. Psychiatr Q. 2005;76(2):13965.

6 Reilly S, Abendstern M, Hughes J, Challis D, Venables D, Pedersen I. Quality in long-term care homes for people with dementia: an assessment of specialist provision. Ageing Soc. 2006;26(4):649-68.

7 Swanson KA, Bastani R, Rubenstein LV, Meredith LS, Ford DE. Effect of mental health care and shared decision making on patient satisfaction in a community sample of patients with depression. Med Care Res Rev. 2007; 64(4):416-30.

8 Hong SI, Morrow-Howell N, Proctor E, Wentz JD, Rubin E. The quality of medical care for comorbid conditions of depressed elders. Aging Ment Health. 2008;12(3):323-32.
9 Grabowski DC, Aschbrenner KA, Rome VF, Bartels SJ. Quality of mental health care for nursing home residents: a literature review. Med Care Res Rev. 2010;67(6):627-56.

10 Cohen J. A power primer. In: Kazden AE, editor. Methodological issues \& strategies in clinical research. 3rd ed. Washington: American Psychological Association; 2003. p. 42736.

11 American Psychiatric Association. Diagnostic and statistical manual of mental disorders (DSM-5 ${ }^{\circledR}$. American Psychiatric Pub; 2013.

12 Baker JA, Richards DA, Campbell M. Nursing attitudes towards acute mental health care: development of a measurement tool. J Adv Nurs. 2005;49(5):522-9.

13 Hamdan-Mansour AM, Wardam LA. Attitudes of Jordanian mental health nurses toward mental illness and patients with mental illness. Issues Ment Health Nurs. 2009;30(11): 705-11.

14 Ahmead MK, Rahhal AA, Baker JA. The attitudes of mental health professionals towards patients with mental illness in an inpatient setting in Palestine. Int J Ment Health Nurs. 2010;19(5):356-62.

15 Clasen C, Meyer C, Brun C, Mase W, Cauley K. Development of the competency assessment tool-mental health, an instrument to assess core competencies for mental health care workers. Psychiatr Rehabil J. 2003;27(1):107.

16 Polit DF, Beck CT. Essentials of nursing research: appraising evidence for nursing practice. Lippincott Williams \& Wilkins; 2009.
17 Bowers L, Brennan G, Flood C, Lipang M, Oladapo P. Preliminary outcomes of a trial to reduce conflict and containment on acute psychiatric wards: City nurses. J Psychiatr Ment Health Nurs. 2006;13(2):165-72.

18 Bowers L, Callaghan P, Nijman H, Paton J, Carr-Walker P, Allan T, et al. The right people for the job: Choosing staff that will adjust positively and productively to working in the new personality disorder (PD) services. Report to the home office, department of mental health and learning disability. London: City University; 2003.

19 Birchwood M, Smith J, Cochrane R, Wetton $\mathrm{S}$, Copestake S. The social functioning scale. The development and validation of a new scale of social adjustment for use in family intervention programmes with schizophrenic patients. Br J Psychiatry. 1990;157(DEC): 853-9.

20 Overall JE, Gorham DR. The brief psychiatric rating scale (BPRS): recent developments in ascertainment and scaling. Psychopharmacol Bull. 1988;24(1):97-9.

21 Waddell L, Taylor M. A new self-rating scale for detecting atypical or second-generation antipsychotic side effects. J Psychopharmacol (Oxford). 2008;22(3):238-43.

22 Attkisson CC, Greenfield TK. Client satisfaction questionnaire- 8 and service satisfaction scale-30. In: Maruish ME, editor. The use of psychological testing for treatment planning and outcome assessment. Lawrence Erlbaum Associates; 1994. p. 402-20.

23 Bryman A. Social research methods. 5th ed. Oxford: Oxford University Press; 2016. 
24 McCambridge J, Witton J, Elbourne DR. Systematic review of the Hawthorne effect: new concepts are needed to study research participation effects. J Clin Epidemiol. 2014;67(3): 267-77.

25 Centre for Multilevel Modelling. Multilevel modelling online course [Internet]. University of Bristol. [cited 2016 Jan 4]. Available from: http://www.bristol.ac.uk/cmm/learning/online-course/

26 Unick GJ, Kessell E, Woodard EK, Leary M, Dilley JW, Shumway M. Factors affecting psychiatric inpatient hospitalization from a psychiatric emergency service. Gen Hosp Psychiatry. 2011;33(6):618-25.

27 Morris A, Bloom JR, Kang S. Organizational and individual factors affecting consumer outcomes of care in mental health services. Adm Policy Ment Health. 2007;34(3):243-53.

28 Akinsulore A, Mapayi BM, Aloba OO, Oloniniyi I, Fatoye FO, Makanjuola RO. Disability assessment as an outcome measure: a comparative study of Nigerian outpatients with schizophrenia and healthy control. Ann Gen Psychiatry. 2015;14(1):40-7.

29 Le TP, Holden JL, Link PC, Granholm EL. Neurocognitive and theory of mind deficits and poor social competence in schizophrenia: the moderating role of social disinterest attitudes. Psychiatry Res. 2018;270:459-66.

30 Paul KI, Moser K. Unemployment impairs mental health: meta-analyses. J Vocat Behav. 2009;74(3):264-82.

31 Awara M, Fasey C. Patients' satisfaction and quality of care in psychiatric out-patient settings. J Mental Health. 2008;17(3):327-35.
32 Razzano LA, Cook JA, Hamilton MM, Hughes TL, Matthews AK. Predictors of mental health services use among lesbian and heterosexual women. Psychiatr Rehabil J. 2006; 29(4):289-98

33 Mendenhall AN. Predictors of service utilization among youth diagnosed with mood disorders. J Child Fam Stud. 2012;21(4):603-11.

34 Killaspy H, Marston L, Omar RZ, Green N, Harrison I, Lean M, et al. Service quality and clinical outcomes: an example from mental health rehabilitation services in England. Br J Psychiatry. 2013;202(1):28-34.

35 Chudleigh C, Naismith SL, Blaszczynski A, Hermens DF, Hodge MA, Hickie IB. How does social functioning in the early stages of psychosis relate to depression and social anxiety? Early Interv Psychiatry. 2011;5(3):22432.

36 Lundqvist LO, Ahlström G, Wilde-Larsson B, Schröder A. The patient's view of quality in psychiatric outpatient care. J Psychiatr Ment Health Nurs. 2012;19(7):629-37.

37 McGurk SR, Meltzer HY. The role of cognition in vocational functioning in schizophrenia. Schizophr Res. 2000;45(3):175-84.

38 Seltzer A, Roncari I, Garfinkel P. Effect of patient education on medication compliance. Can J Psychiatry. 1980;25(8):638-45.

39 Bener A, Ghuloum S. Gender difference on patients' satisfaction and expectation towards mental health care. Niger J Clin Pract. 2013; 16(3):285-91.

40 Längle G, Baum W, Wollinger A, Renner G, U'ren R, Schwärzler F, et al. Indicators of quality of in-patient psychiatric treatment: the patients' view. Int J Qual Heal Care. 2003; 15(3):213-21.
41 Ruggeri M, Lasalvia A, Bisoffi G, Thornicroft $\mathrm{G}$, Vàzquez-Barquero JL, Becker T, et al. Satisfaction with mental health services among people with schizophrenia in five European sites: results from the EPSILON study. Schizophr Bull. 2003;29(2):229-45.

42 Doran DI, Sidani S, Keatings M, Doidge D. An empirical test of the nursing role effectiveness model. J Adv Nurs. 2002;38(1):29-39.

43 Khomeiran RT, Yekta ZP, Kiger AM, Ahmadi F. Professional competence: factors described by nurses as influencing their development. Int Nurs Rev. 2006;53(1):66-72.

44 Almalki M, FitzGerald G, Clark M. Health care system in Saudi Arabia: an overview. EMHJEastern Mediterr Heal J. 2011;17(10):784-93.

45 Aiken LH, Sloane DM, Bruyneel L, Van den Heede K, Griffiths P, Busse R, et al. Nurse staffing and education and hospital mortality in nine European countries: a retrospective observational study. Lancet. 2014;383(9931): 1824-30.

46 Olusina AK, Ohaeri JU, Olatawura MO. The quality of interactions between staff and psychiatric inpatients in a Nigerian general hospital. Psychopathology. 2003;36(5):269-75.

47 Sandford DA, Elzinga RH. Patient interactions in four psychiatric wards. Acta Psychiatr Scand. 1990;82(2):125-9.

48 Holmqvist R. Associations between staff feelings toward patients and treatment outcome at psychiatric treatment homes. J Nerv Ment Dis. 2000;188(6):366-71.

49 Tyson PJ. A service user-initiated project investigating the attitudes of mental health staff towards clients and services in an acute mental health unit. J Psychiatr Ment Health Nurs. 2013;20(5):379-86. 